\section{Marta Ferrer-García}

Department of Personality,

Assessment and Psychological

Treatments

University of Barcelona

08035 Barcelona, Spain

Olaya García-Rodríguez*

Department of Psychology

University of Oviedo

Oviedo, Spain

\section{Irene Pericot-Valverde}

Department of Personality,

Assessment and Psychological

Treatments

University of Barcelona

08035 Barcelona, Spain

\section{Jin H. Yoon}

Department of Psychiatry and

Behavioral Sciences

Baylor College of Medicine

Houston, Texas, 77030, USA

\section{Roberto Secades-Villa}

Department of Psychology

University of Oviedo

Oviedo, Spain

\section{José Gutiérrez-Maldonado}

Department of Personality,

Assessment and Psychological

Treatments

University of Barcelona

08035 Barcelona, Spain

\section{Predictors of Smoking Craving During Virtual Reality Exposure}

\begin{abstract}
Cue exposure treatment (CET) consists of controlled and repeated exposure to drugrelated stimuli in order to reduce cue-reactivity. Virtual reality $(V R)$ has proved to be a promising tool for exposition. However, identifying the variables that can modulate the efficacy of this technique is essential for selecting the most appropriate exposure modality. The aim of this study was to determine the relation between several individual variables and self-reported craving in smokers exposed to VR environments. Fortysix smokers were exposed to seven complex virtual environments that reproduce typical situations in which people smoke. Self-reported craving was selected as the criterion variable and three types of variables were selected as the predictor variables: related to nicotine dependence, related to anxiety and impulsivity, and related to the sense of presence in the virtual environments. Sense of presence was the only predictor of self-reported craving in all the experimental virtual environments. Nicotine dependence variables added predictive power to the model only in the virtual breakfast at home. No relation was found between anxiety or impulsivity and self-reported craving. Virtual reality technology can be very helpful for improving CET for substance use disorders. However, the use of virtual environments would make sense only insofar as the sense of presence was high. Otherwise, the effectiveness of exposure might be affected.
\end{abstract}

\section{Introduction}

Despite the existence of empirically validated psychological and pharmacological treatments for tobacco addiction (Fiore, 2000), high relapse rates show the need to incorporate more effective strategies for maintaining abstinence. Previous research has highlighted the association between relapse and exposure to drug-related cues that elicit craving (Marlatt \& Gordon, 1985; Piasecki, 2006). Cue exposure treatment (CET) consists of controlled and repeated exposure to drug-related stimuli in order to reduce cue-reactivity, and has been used for craving extinction in opiate and alcohol addiction (Kasvikis, Bradley, Powell, Marks, \& Gray, 1991; Powell, Gray, \& Bradley, 1993). Given that tobacco use is related to many everyday situations, it would be necessary to extinguish associations between smoking craving and such situations, but few CET studies have focused on tobacco cessation. This may be due to the difficulty of achieving exposure to such a wide range of situations using traditional methods. In recent years, there have been increased numbers of studies assessing the utility of virtual reality (VR) for improving CET. VR environments simulate typical situations associated

\footnotetext{
*Correspondence to garciaolaya@uniovi.es.
}

Presence, Vol. 21, No. 4, Fall 2012, 423-434 (.) 2012 by the Massachusetts Institute of Technology 
with tobacco use, and may be effective for smoking cessation (García-Rodríguez, Pericot-Valverde, GutiérrezMaldonado, \& Ferrer-García, 2009). Previous studies have successfully used VR to provoke craving in smokers (Baumann \& Sayette, 2006; Traylor, Bordnick, \& Carter, 2009; Bordnick, Graap, Copp, Brooks, \& Ferrer, 2005; Bordnick et al., 2004).

Nevertheless, in addition to assessing the ability of VR environments to generate craving responses, it is essential to identify the variables that can modulate these responses while subjects are engaged in the virtual situation, with a view to selecting the appropriate exposure tools.

Several factors can influence cigarette craving. Previous research suggests that impulsivity is associated with smoking behavior. Several studies have found that smokers tend to be more impulsive than nonsmokers (Kassel, Shiffman, Gnys, Paty, \& Zettler-Segal, 1994), and that impulsive smokers appear to find it harder to quit than nonimpulsive smokers (Doran, Spring, McChargue, Pergadia, \& Richmond, 2004). It has been hypothesized that the relationship between impulsivity and cigarette smoking could be mediated by cue-induced craving, and previous studies have shown that impulsive smokers report significantly higher levels of craving (Doran, McChargue, \& Spring, 2008; Doran, Spring, \& McChargue, 2007).

Likewise, several studies suggest that anxiety or stress are related to smoking craving (Childs \& de Wit, 2010; Karg, 2002). In recent research, Childs and de Wit found that increases in acute psychosocial stress also increased cigarette craving. Similarly, Watson and colleagues found that higher rates of social anxiety symptoms and several behaviors associated with smoking to cope with these symptoms predicted increases in craving during nicotine deprivation (Watson, VanderVeen, Cohen, DeMarree, \& Morrell, 2012). On the other hand, DiFranza and colleagues (2004) found a strong association between anxiety as a general psychological trait and the craving to use tobacco to cope with stressful situations. Also, those participants who felt relaxed in response to their first exposure to nicotine were more likely to report smoking craving caused by stress. Studies highlight that heightened anxiety increases the perception of aversive physiological and affective sensations, thereby increasing the motivation to engage in behaviors aimed at reducing these aversive states, such as smoking. However, not all research has found a relationship between anxiety and craving (Canals, Domènech, \& Bladé, 1996; Kick \& Cooley, 1997).

Smoking craving also appears to be associated with nicotine dependence (Killen, Fortmann, Kraemer, Varady, \& Newman, 1992; Tagmat, Wolff, Ruege, John, \& Thyrian, 2010). Vollstädt-Klein and colleagues (2010) studied cue-elicited craving in smokers exposed to tobacco advertisements. They found that moderately dependent smokers were particularly responsive to tobacco advertising, while smoking craving in heavily dependent smokers was stable over time. The authors suggested that cue reactivity in heavily dependent smokers would be elicited by internal rather than external cues. On the other hand, in moderately dependent smokers, cue reactivity would be elicited by external cues such as tobacco advertising. Tagmat, Wolff, Ruege, John, and Thyrian (2010) also found differences in cue-elicited craving between daily smokers and occasional smokers. These authors found that daily smokers showed a higher smoking urge in habitual smoking situations compared to positive-social and negative-affective situations, while occasional smokers showed a higher smoking urge in positive-social and negative-affective situations than in habitual situations.

Finally, research on VR and its application in clinical psychology suggests that there is a strong reciprocal association between the sense of presence experienced in virtual environments and the emotional reactivity of users in these situations (Robillard, Bouchard, Fournier, \& Renaud, 2003). Presence is understood as the "sense of being" in the virtual environment-the feeling that the virtual environment is the dominant reality and is experienced by users as a place they are visiting (Slater, Steed, McCarthy, \& Maringelli, 1998).

Given that impulsivity, anxiety, and nicotine dependence have been associated with smoking craving, the aim of this study was to assess the ability of these variables to predict self-reported craving in smokers during exposure to virtual environments. As we used virtual reality tech- 
Lunch at home

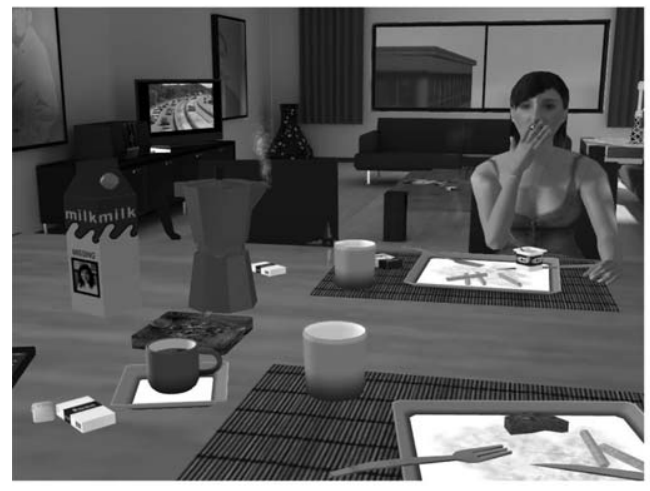

Bus

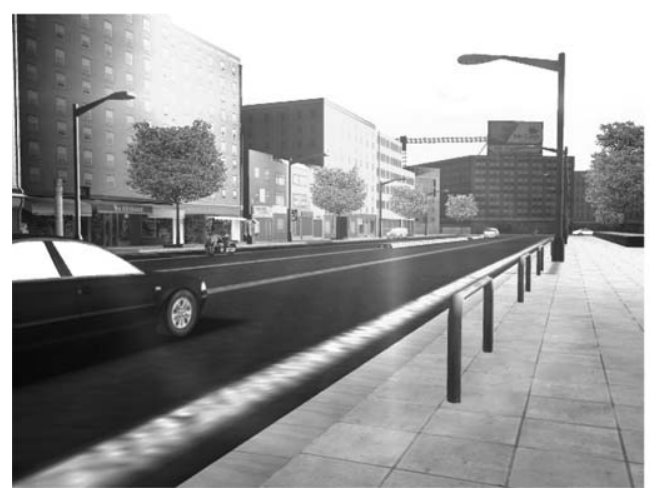

Figure I. Some captures of the virtual environments

nology, we also assessed the predictive power of sense of presence.

\section{Methods}

\section{I Participants}

Participants were 46 volunteer smokers recruited by means of the snowball sampling method for the Virtual Reality Laboratory at the University of Barcelona. All provided informed consent before participating in the study. The sample was composed of 26 males and 20 females aged 18 to $60(M=28.76, S D=12.57)$. The average Fagerström Test score for Nicotine Dependence (FTND) was $3.38(S D=1.87)$, and the mean number of cigarettes smoked per day was $15.57(S D=5.38)$. Inclusion criteria for participation were age 18 or over and a minimum smoking rate of 10 cigarettes per day. Prospective participants were excluded if they met crite-

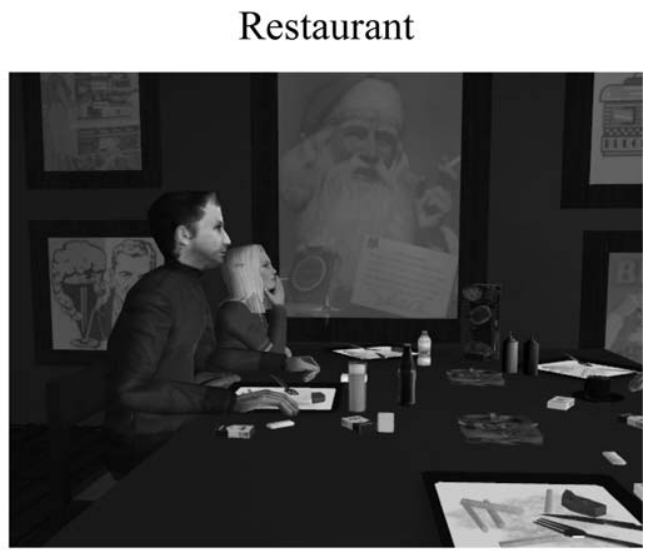

Pub

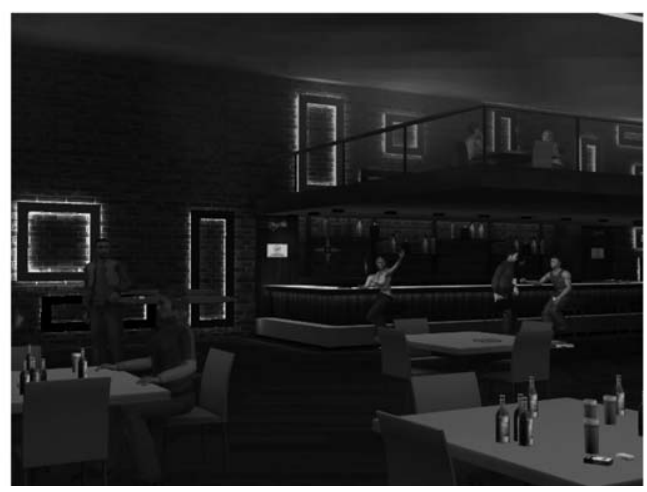

ria for a current severe psychiatric disorder or other substance dependence, if they had a smoking-related illness, or if they were currently involved in smoking cessation activity.

\subsection{Instruments and Variables}

2.2.I Virtual Environments. Seven VR environments with smoking-related cues were used: being in a pub, having lunch at home, having breakfast at home, having a coffee at a cafe, after having lunch at a restaurant, waiting in the street, and watching TV at night (see Figure 1). These virtual environments were developed using several modeling and interactive application tools. The scenarios, the animated objects they contained, and the avatars were created using 3D Studio Max. Textures were made with Adobe Photoshop. Finally, Virtools Dev was used to integrate all virtual elements, textures, and 
sounds, and to make the environment interactive. Environments were presented by means of a head-mounted display (5DT HMD 800 Series) with tracking sensors that allowed users to change the orientation of viewpoints with their head movements, and maximum screen resolution $(1,366 \times 768)$. A standard mouse device was used for the interactions with objects and avatars during the exposure. Each environment experience lasted $6 \mathrm{~min}$.

The VR environments were developed on the basis of a previous study (García-Rodríguez et al., 2011) aimed at identifying frequent situations that produce smoking craving, as well as detecting specific craving cues in those contexts. In the environment breakfast at home, participants woke up and took a shower. After that, they could have breakfast while watching TV. In the environments lunch at home and restaurant, participants were finishing having lunch with friends who smoke. In the virtual café, participants were having a coffee with a friend who smokes. In the environment at home at night, participants were watching TV or listening to music at home. The virtual $p u b$ had lot of people and loud music. The avatars were smoking, having a drink, dancing, talking, or playing pool. Participants could go around the pub and have a drink at the bar. In the bus environment, participants were waiting near a bus stop. There were avatars smoking and a street vendor selling tobacco products. In all the virtual environments there were paraphernalia related to tobacco (cigarettes, ashtrays, etc.), and people who offered cigarettes to the participant (with the exception of the environments breakfast at home and at home at night, where there were no avatars). It should also be noted that all the environments used in this study were shown in a seminal study to be able to produce craving in smokers (García-Rodríguez, Pericot-Valverde, Gutiérrez-Maldonado, Ferrer-García, \& Secades-Villa, 2012).

2.2.2 Dependent Variable. Subjective craving was assessed with a visual analogical scale (VAS) built into the virtual environments. Participants were required to rate the strength of their desire to smoke at that moment, from 0 (no desire) to 100 (highly intense desire). Craving was assessed once per minute throughout the exposure. The average of all VAS scores obtained during exposure to each virtual environment was used to indicate subjective smoking craving experienced in that situation. VAS scores have been previously used in several studies for measuring smoking craving (Guthrie, Ni, Zubieta, Teter, \& Domino, 2004; Kaganoff, Bordnick, \& Carter, 2012; Mendelson, Goletiani, Sholar, Siegel, \& Mello, 2008). The use of self-report craving, assessed as a single measure of the desire to smoke at that moment, has been previously validated (Rosenberg, 2009).

\subsubsection{Independent Variables.}

\subsubsection{Nicotine Dependence Related Variables.}

Cigarettes Per Day (CPD) was recorded for each participant

Fagerström Test for Nicotine Dependence (FTND)

The FTND is a six-item self-report scale that sums behavioral responses suggestive of physiological dependence on nicotine, such as time to first cigarette after waking up and smoking when ill.

\section{Carbon monoxide (CO)}

The Micro+ Smokerlyzer (Bedfont Technical Instruments) was used to assess CO levels. This device collects samples of exhaled air through the sensor surface and reports alveolar carbon monoxide levels in parts per million (ppm).

2.2.3.2 Anxiety and Impulsivity. The State-Trait Anxiety Inventory (Spielberger, Gorsuch, \& Lushene, 1970) was used to assess anxiety. This questionnaire comprises two separate self-report scales that measure two independent conceptions of anxiety, as a state and as a trait.

\section{Delay Discounting Task (DDT)}

Delay discounting refers to the fact that a reward is valued more than the same reward if it occurs sometime in the future. This paradigm operationally describes the rate at which reinforcers lose value with increasing delay of their being received (Yoon, Higgins, \& Heil, 2007), and is considered a measure of impulsivity (Bickel \& Marsch, 2001). The standard DDT involves a situation in which the subject must choose to receive a reinforcer 
(usually money) available at that time or a higher-value reinforcer available after a fixed delay. A computerized DDT was administered to participants, and $k$ values were calculated by finding the best fit of the indifference points for each participant to the Mazur hyperbolic equation (Mazur, 1987).

\subsubsection{Sense of Presence. To assess the sense of} presence, we used the Presence Questionnaire (PQ; Slater et al., 1998). This questionnaire evaluates the degree to which the subject has experienced the sense of being in the virtual environment, how far the virtual environment is the dominant reality and how far it is recalled as a place.

\subsection{Procedure}

Once the informed consent form was signed, and before initiating the experiment, participants were asked to smoke one cigarette in order to match nicotine levels among participants. Information on demographics and cigarette use level was collected and $\mathrm{CO}$ was measured. The FTND, the STAI, and the DDT were then administered. Before entering the experimental virtual environments, participants were exposed to a virtual training scenario in which they received instructions on how to move and interact in the virtual world, as well as how to input commands. After the training task, participants were exposed to the seven virtual environments, displayed randomly. The VAS score was recorded once per minute during the exposure. After the exposure to the seven environments, the sense of presence was assessed.

\subsection{Statistical Analysis}

Given the small sample size, it was not possible to carry out a multiple regression analysis entering all the selected predictors simultaneously. Instead, several simple and multiple regression analyses were performed grouping the independent variables according to what they were measuring. The mean for self-reported craving in each virtual environment was used as the dependent variable. First, a multiple regression analysis was carried out with entry of all nicotine dependence variables: carbon monoxide, number of cigarettes smoked daily, and Fagerström Questionnaire scores. Second, another mul- tiple regression analysis was performed entering anxiety as a trait and anxiety as a state. Third, a simple regression analysis was conducted entering impulsivity. Fourth, a simple regression analysis was carried out entering the sense of presence experienced in the VEs as the predictor. Finally, a multiple regression analysis was performed with all the predictor variables that previous analyses had shown to be possible predictors of self-reported craving.

\section{Results}

Table 1 shows the results of the multiple regression analysis carried out to explore the relationship between nicotine dependence and level of craving experienced in the virtual environments. We considered three indicators of dependence: CO level, number of cigarettes smoked daily (CPD), and Fagerström Questionnaire score (FTND).

The resulting model was a significant predictor of the craving experienced only in the virtual environment that simulated breakfast at home, explaining $24.6 \%$ of the variance. Score obtained on the FTND was the only variable that made a statistically significant contribution to the prediction of craving in this situation.

Tables 2 and 3 show the results with anxiety and impulsivity variables. Neither anxiety nor impulsivity was a significant predictor of the smoking craving experienced in any of the environments.

The sense of presence was a significant predictor of the smoking craving experienced in all of the virtual environments. As shown in Table 4, presence explained $10 \%$ of the variance in "breakfast at home," $35 \%$ of the variance in "lunch at home," $15 \%$ of the variance in "watching TV at night," $23 \%$ of the variance in "the pub," $15 \%$ of the variance in "waiting in the street," $20 \%$ of the variance in "the cafe," and $21 \%$ of the variance in "the restaurant."

Given that sense of presence was the only independent variable that systematically predicted craving in all the VEs, and that nicotine dependence, specifically FTND, predicted craving in the virtual breakfast at home, a stepwise multiple regression was carried out entering both variables. In the virtual breakfast at home, a first model was obtained including the FTND. This variable 
Table I. Summany of Multiple Regression Analyses for Nicotine Dependence Variables Predicting Smoking Craving Experienced in Each Virtual Environment

\begin{tabular}{|c|c|c|c|c|c|c|c|}
\hline Predictors & Beta & $t$ & $p$ & $R^{2}$ & $R^{2}$ adj. & $F$ & $p$ \\
\hline Breakfast at home & & & & .30 & .25 & 5.68 & .002 \\
\hline $\mathrm{CO}$ & -.23 & -1.58 & .12 & & & & \\
\hline FTND & .52 & 3.31 & .002 & & & & \\
\hline CPD & .05 & .29 & .77 & & & & \\
\hline Lunch at home & & & & .13 & .06 & 1.95 & .14 \\
\hline $\mathrm{CO}$ & -.37 & -2.3 & .02 & & & & \\
\hline FTND & .06 & .36 & .72 & & & & \\
\hline CPD & .05 & .25 & .80 & & & & \\
\hline At home at night & & & & .13 & .07 & 2.01 & .13 \\
\hline $\mathrm{CO}$ & -.39 & -2.43 & .02 & & & & \\
\hline FTND & -.01 & -.05 & .96 & & & & \\
\hline CPD & .21 & 1.12 & .27 & & & & \\
\hline Pub & & & & .10 & .03 & 1.51 & .23 \\
\hline $\mathrm{CO}$ & -.31 & -1.90 & .06 & & & & \\
\hline FTND & .12 & .69 & .49 & & & & \\
\hline CPD & -.03 & -.16 & .87 & & & & \\
\hline Bus & & & & .10 & .03 & 1.51 & .23 \\
\hline $\mathrm{CO}$ & -.33 & -2.05 & .05 & & & & \\
\hline FTND & .04 & .25 & .81 & & & & \\
\hline CPD & .18 & .93 & .36 & & & & \\
\hline Cafe & & & & .10 & .04 & 1.58 & .21 \\
\hline $\mathrm{CO}$ & -.28 & -1.74 & .09 & & & & \\
\hline FTND & .14 & .80 & .43 & & & & \\
\hline CPD & .18 & .96 & .34 & & & & \\
\hline Restaurant & & & & .05 & -.02 & .66 & .58 \\
\hline $\mathrm{CO}$ & -.22 & -1.34 & .19 & & & & \\
\hline FTND & .07 & .38 & .70 & & & & \\
\hline CPD & .04 & .19 & .85 & & & & \\
\hline
\end{tabular}

explained $25 \%$ of the variance in smoking craving experienced (see Table 5). A second model including both sense of presence and FTND explained $41 \%$ of the variance. On the other hand, only the sense of presence variable showed a unique significant contribution to the prediction of craving in the remaining situations. Specifically, the sense of presence explained $36 \%$ of the variance in the virtual lunch at home, $17 \%$ of the variance in the virtual "watching TV at night," $25 \%$ of the variance in the virtual pub, $17 \%$ of the variance in the virtual bus sta- tion ("waiting in the street"), $21 \%$ of the variance in the virtual cafe, $23 \%$ of the variance in the virtual restaurant, and $17 \%$ of the variance on averaging the craving experienced in all conditions.

\section{Discussion}

The aim of this study was to assess the ability of impulsivity, anxiety, nicotine dependence, and sense of 
Table 2. Summary of Multiple Regression Analyses for Anxiety Variables Predicting Smoking Craving Experienced in

Each Virtual Environment

\begin{tabular}{|c|c|c|c|c|c|c|c|}
\hline Predictors & Beta & $t$ & $p$ & $R^{2}$ & $R^{2}$ adj. & $F$ & $p$ \\
\hline Breakfast at home & & & & .08 & .04 & 1.88 & .16 \\
\hline STAI-S & .17 & 1.08 & .29 & & & & \\
\hline STAI-T & .17 & 1.08 & .29 & & & & \\
\hline Lunch at home & & & & .10 & .06 & 2.27 & .12 \\
\hline STAI-S & .33 & 2.08 & .04 & & & & \\
\hline STAI-T & -.19 & -1.21 & .23 & & & & \\
\hline At home at night & & & & .04 & -.01 & .88 & .42 \\
\hline STAI-S & .18 & 1.09 & .28 & & & & \\
\hline STAI-T & -.18 & -1.11 & .27 & & & & \\
\hline Pub & & & & .04 & -.005 & .89 & .42 \\
\hline STAI-S & .20 & 1.18 & .24 & & & & \\
\hline STAI-T & -.17 & -1.02 & .31 & & & & \\
\hline Bus & & & & .10 & .05 & 2.22 & .12 \\
\hline STAI-S & .30 & 1.89 & .06 & & & & \\
\hline STAI-T & .02 & .13 & .90 & & & & \\
\hline Cafe & & & & .10 & .06 & 2.35 & .11 \\
\hline STAI-S & .29 & 1.82 & .08 & & & & \\
\hline STAI-T & .06 & .39 & .70 & & & & \\
\hline Restaurant & & & & .04 & -.01 & .86 & .43 \\
\hline STAI-S & .21 & 1.30 & .20 & & & & \\
\hline STAI-T & -.06 & -.34 & .73 & & & & \\
\hline
\end{tabular}

Table 3. Summary of Simple Regression Analyses for Impulsivity Predicting Smoking Craving Experienced in Each Virtual Environment

\begin{tabular}{lcccccrc}
\hline Predictor: Impulsivity & Beta & \multicolumn{1}{l}{$t$} & $p$ & $R^{2}$ & $R^{2}$ adj. & \multicolumn{1}{c}{$F$} & $p$ \\
\hline Breakfast at home & -.10 & -.62 & .54 & .01 & -.01 & .38 & .54 \\
Lunch at home & -.27 & -1.8 & .08 & .07 & .05 & 3.24 & .08 \\
At home at night & -.14 & -.91 & .37 & .02 & -.004 & .83 & .37 \\
Pub & -.29 & -1.98 & .05 & .09 & .06 & 3.92 & .05 \\
Bus & -.23 & -1.51 & .14 & .05 & .03 & 2.29 & .14 \\
Cafe & -.20 & -1.35 & .18 & .04 & .02 & 1.83 & .18 \\
Restaurant & -.24 & -1.60 & .12 & .06 & .04 & 2.58 & .12 \\
\hline
\end{tabular}

presence to predict self-reported craving in smokers during exposure to virtual environments.

As seen in Section 3, the sense of presence constitutes a good predictor of smoking craving experienced in virtual environments. Those participants who experienced smoking-related VEs as though they were in real-life situations showed higher levels of craving than participants who did not feel a sufficient sense of presence in the virtual situations. These results are in line with those of previous research in which a high level of experienced sense 
Table 4. Summary of Simple Regression Analyses for Sense of Presence Predicting Smoking Craving Experienced in Each Virtual Environment

\begin{tabular}{llllllrc}
\hline Predictor: Sense of presence & Beta & $t$ & \multicolumn{1}{l}{$p$} & $R^{2}$ & $R^{2}$ adj. & \multicolumn{1}{c}{$F$} & $p$ \\
\hline Breakfast at home & .35 & 2.40 & .02 & .12 & .10 & 5.79 & .02 \\
Lunch at home & .60 & 4.91 & $<.001$ & .36 & .35 & 24.07 & $<.001$ \\
At home at night & .41 & 2.91 & .006 & .17 & .15 & 8.47 & .006 \\
Pub & .50 & 3.75 & .001 & .25 & .23 & 14.04 & .001 \\
Bus & .41 & 2.92 & .006 & .17 & .15 & 8.53 & .006 \\
Cafe & .46 & 3.42 & .001 & .21 & .20 & 11.70 & .001 \\
Restaurant & .48 & 3.58 & .001 & .23 & .21 & 12.80 & .001 \\
\hline
\end{tabular}

Table 5. Summary of Stepwise Multiple Regression Analyses for Sense of Presence and Nicotine Dependence (FTND) Variables Predicting Smoking Craving Experienced in Each Virtual Environment

\begin{tabular}{|c|c|c|c|c|c|c|c|}
\hline Model & Predictors & Beta & $t$ & $p$ & $R^{2}$ Ch. & $F \mathrm{Ch}$. & pCh. \\
\hline \multicolumn{8}{|c|}{ Breakfast at home } \\
\hline \multirow[t]{2}{*}{1} & FTND & .50 & 3.78 & $<.001$ & .25 & 14.27 & $<.001$ \\
\hline & FTND & .54 & 4.45 & $<.001$ & & & \\
\hline \multirow[t]{2}{*}{2} & & & & & .15 & 10.67 & .002 \\
\hline & Presence & .39 & 3.27 & .002 & & & \\
\hline \multicolumn{8}{|c|}{ Lunch at home } \\
\hline 1 & Presence & .60 & 4.91 & $<.001$ & .36 & 24.07 & $<.001$ \\
\hline \multicolumn{8}{|c|}{ At home at night } \\
\hline 1 & Presence & .41 & 2.91 & .006 & .17 & 8.47 & .006 \\
\hline \multicolumn{8}{|l|}{ Pub } \\
\hline 1 & Presence & .50 & 3.75 & .001 & .25 & 14.04 & .001 \\
\hline \multicolumn{8}{|l|}{ Bus } \\
\hline 1 & Presence & .41 & 2.92 & .006 & .17 & 8.53 & .006 \\
\hline \multicolumn{8}{|l|}{ Cafe } \\
\hline 1 & Presence & .46 & 3.42 & .001 & .21 & 11.70 & .001 \\
\hline \multicolumn{8}{|c|}{ Restaurant } \\
\hline 1 & Presence & .48 & 3.58 & .001 & .23 & 12.80 & .001 \\
\hline \multicolumn{8}{|c|}{ Averaged craving } \\
\hline 1 & Presence & .41 & 2.95 & .005 & .17 & 8.68 & .005 \\
\hline
\end{tabular}

of presence was related to a stronger reactivity in participants on being exposed to virtual cues (Bordnick et al., 2008; Gorini, Griez, Petrova, \& Riva, 2010; Robillard, 2003).

Among the other variables analyzed, only the FTND score showed predictive power for smoking craving. Specifically, in the virtual environment that simulated breakfast at home, this nicotine dependence variable made the largest single significant contribution to the prediction of craving. Given that smoking early in the morning is a strong indicator of nicotine dependence (Fagerström, 2003 ), is not surprising that it was precisely in the breakfast situation that participants with higher levels of nicotine dependence showed higher levels of cigarette craving. As Fagerström (2003) remarks, all smokers generally wake up in a state of nicotine deprivation (after 
approximately $8 \mathrm{hr}$ of sleeping). Taking this into account, the drive to light up quickly is a good marker for nicotine dependence, and it makes sense that FTND was a significant predictor in the breakfast environment.

Impulsivity and anxiety do not predict craving in this study. The lack of predictive power of anxiety variables (both trait and state) could be explained by the fact that all participants in this study are daily smokers (minimum 10 CPD). Tagmat and colleagues (2010) found that smoking craving was related to negative-affective situations only in occasional smokers, and not in daily smokers. Participants in this study probably experience smoking craving in habitual situations, rather than specifically when they experience high levels of anxiety.

Some implications of these results should be mentioned. First of all, the psychological traits usually associated with smoking behavior (anxiety and impulsivity) did not emerge as relevant in this study. Therefore, regardless of participant characteristics in these traits, virtual reality environments are able to produce craving. Also, only the breakfast environment was affected by the level of nicotine dependence. This suggests that this environment may only be suitable for those patients with high levels of dependency, and not for just any kind of smoker. In contrast, the sense of presence emerged as the best predictor in the analysis, suggesting the need to evaluate this variable and take it into account on using VR environments under the CET paradigm.

There is no single, consensus definition of sense of presence. Initially, presence was primarily related to technological aspects. Thus, increasing immersion in virtual environments through the use of devices that produce greater involvement, improving the realism of graphics, and increasing the possibilities of interaction in the virtual world, were the main ways of enhancing presence. The possibility of including contextual and complexity cues in VR environments also contributes to increasing experienced sense of presence. It has been suggested that current non-VR cue exposure methods fail to provide exposure beyond proximal cues, leaving out context and complex cues, and thus failing to extinguish craving in the real world (Bordnick, Traylor, Carter, \& Graap, 2012; Kaganoff et al., 2012). This has been a possible reason for poor results obtained from CET studies using cue exposure techniques. VR can solve these issues by providing exposure to all three of these cue types: proximal, contextual, and complex.

It is now accepted that presence is a multidimensional concept, and that psychological, social, and cultural factors should also be considered in its definition. According to Mantovani and Castelnuovo (2003), "the psychological state of presence could be described as a subjective feeling depending on many environmental, contextual, and personal characteristics and factors." Therefore, personal factors such as the ability to imagine and to identify with the virtual self, the user's emotional state and motivation, and contextual factors such as the ecological validity or plausibility of the virtual situation, play an important role in eliciting the sense of presence.

Given the results obtained in this study, there is a clear need and opportunity to develop strategies for improving these aspects, with a view to increasing the sense of presence in virtual environments, and thus enhancing the effectiveness of such environments to produce craving.

There are some limitations in this study that should be considered. First, the small sample size did not allow for the use of a multiple regression analysis to simultaneously enter all the selected predictors. Instead, several simple and multiple linear regression analyses were performed, grouping the independent variables according to what they were measuring. In view of this, the predictive power of potential interactions between independent variables may have been underestimated. For this same reason, the effect of possible independent variables, such as sex or age, was not considered. Second, the study relied on participants' self-reports. Even so, this form of measuring craving has been validated previously, showing good psychometric functioning (Rosenberg, 2009). And third, the generalization potential of the results obtained may be limited by the participant eligibility criteria used. For these reasons, future research should explore the effects of other individual variables on the efficacy of VR exposure, as well as the effects of aspects directly related to the use of technology, such as previous experience of virtual reality environments or skills with similar technology. The sense of presence was assessed for this study just once, following the first experience 
with virtual reality environments for most of the participants. Even so, it is not clear whether or not this variable can be modified through experience and training. Further research must be carried out to clarify how this variable can be modified, and whether this might affect the ability of VR environments to produce craving.

Overall, virtual reality technology appears to be a promising tool that can be used to improve CET for substance use disorders, and no individual variable apart from the sense of presence appears to interfere with the capacity of the VR environments to trigger craving. Therefore, the use of virtual environments would be a feasible option for any sample of participants who could be immersed in them with a minimum sense of presence. Should this minimum criterion fail to be met, the effectiveness of virtual exposure might be affected, and other exposure modalities should be considered as better options.

\section{Acknowledgments}

This work was supported by the Ministry of Science and Innovation (MICIIN) grant funded by the Spanish Government, Ref. PSI2008-05938/PSIC.

\section{References}

Baumann, S. B., \& Sayette, M. A. (2006). Smoking cues in a virtual world provoke craving in cigarette smokers. Psychology of Addictive Behaviors, 20, 484-489. doi:10.1037/0893164X.20.4.484

Bickel, W. K., \& Marsch, L. A. (2001). Toward a behavioral economic understanding of drug dependence: Delay discounting processes. Addiction, 96, 73-86. doi:10.1080/ 09652140020016978

Bordnick, P. S., Graap, K. M., Copp, H. L., Brooks, J., \& Ferrer, M. (2005). Virtual reality cue reactivity assessment in cigarette smokers. CyberPsychology \& Behavior, 8(5), 487492. doi:10.1089/cpb.2005.8.487

Bordnick, P. S., Graap, K. M., Copp, H., Brooks, J., Ferrer, M., \& Logue, B. (2004). Utilizing of virtual reality to standardize nicotine craving research: A pilot study. Addictive Behaviors, 29(9), 1889-1894. doi:10.1016/j.addbeh. 2004.06.008
Bordnick, P. S., Traylor, A., Carter, B. L., \& Graap, K. M. (2012). A feasibility study of virtual reality-based coping skills training for nicotine dependence. Research on Social Work Practice, 22, 293-300.

Bordnick, P. S., Traylor, A., Coop, H. L., Graap, K. M., Carter, B., Ferrer, M., et al. (2008). Assessing reactivity to virtual reality alcohol based cues. Addictive Behaviors, 33, 743-756. doi:10.1016/j.addbeh.2007.12.010

Bordnick, P. S., Traylor, A. C., Graap, K. M., Copp, H. L., \& Brooks, J. (2005). Virtual reality cue reactivity assessment: A case study in a teen smoker. Applied Psychophysiology and Biofeedback, 30, 187-193. doi:10.1007/s10484-0056376-0

Canals, J., Domènech, E., \& Bladé, J. (1996). Smoking and trait anxiety. Psychological Reports, 79, 809-810. doi:10.2466/pr0.1996.79.3.809

Childs, E., \& de Wit, H. (2010). Effect of acute psychosocial stress on cigarette craving and smoking. Nicotine \& Tobacco Research, 12, 449-453. doi:10.1093/ntr/ntp214

DiFranza, J. R., Savageau, J. A., Rigotti, N. A., Ockene, J. K., McNeill, A. D., Coleman, M., et al. (2004). Trait anxiety and nicotine dependence in adolescents. A report from the DANDY study. Addictive Behaviors, 29, 911-919. doi:10.1016/j.addbeh.2004.02.021

Doran, N., McChargue, D., \& Spring, B. (2008). Effect of impulsivity on cardiovascular and subjective reactivity to smoking cues. Addictive Behaviors, 33, 167-172. doi:10.1016/j.addbeh.2007.05.009

Doran, N., Spring, B., \& McChargue, D. (2007). Effect of impulsivity on craving and behavioral reactivity to smoking cues. Psychopharmacology, 194, 279-288. doi:10.1007/ s00213-007-0832-x

Doran, N., Spring, B., McChargue, D., Pergadia, M., \& Richmond, M. (2004). Impulsivity and relapse to cigarette smoking. Nicotine \& Tobacco Research, 6, 641-647. doi:10.1080/ 14622200410001727939

Fagerström, K. (2003). Time to first cigarette: The best single indicator of tobacco dependence? Monaldi Archives of Chest Diseases, 59, 91-94.

Fiore, M. C. (2000). A clinical practice guideline for treating tobacco use and dependence: A US Public Health Service report. Journal of the American Medical Association, 283, 3244-3254.

García-Rodríguez, O., Ferrer-García, M., Pericot-Valverde, I., Gutiérrez-Maldonado, J., Secades-Villa, R., \& Carballo, J. L. (2011). Identifying specific cues and contexts related to smoking craving for the development of effective virtual 
environments. CyberPsychology \& Behavior, 14, 91-97. doi:10.1089/cyber.2010.0012

García-Rodríguez, O., Pericot-Valverde, I., Gutiérrez-Maldonado, J., \& Ferrer-García, M. (2009). La Realidad Virtual como estrategia para la mejora de los tratamientos del tabaquismo [Virtual Reality as a strategy to improve smoking treatment]. Health and Addictions, 9, 39-55.

García-Rodríguez, O., Pericot-Valverde, I., Gutiérrez-Maldonado, J., Ferrer-García, M., \& Secades-Villa, R. (2012). Validation of smoking-related virtual environments for cue exposure therapy. Addictive Behaviors, 37, 703-708.

Gorini, A., Griez, E., Petrova, A., \& Riva, G. (2010). Assessment of the emotional responses produced by exposure to real food, virtual food and photographs of food in patients affected by eating disorders. Annals of General Psychiatry, 9 . doi:10.1186/1744-859X-9-30

Guthrie, S. K., Ni, L., Zubieta, J. K., Teter, C. J., \& Domino, E. F. (2004). Changes in craving for a cigarette and arterial nicotine plasma concentrations in abstinent smokers. Progress in Neuro-Psychopharmacology \& Biological Psychiatry, 28, 617-623.

Kaganoff, E., Bordnick, P. S., \& Carter, B. L. (2012). Feasibility of using virtual reality to assess nicotine cue reactivity during treatment. Research on Social Work Practice, 22, 159-165.

Karg, R. S. (2002). The effects of stress and smoking-related cues on craving to smoke among abstinent and nonabstinent cigarette smokers. Dissertation Abstracts International, Section B: The Science and the Engineering, 63(6-B), 3010 .

Kassel, J. D., Shiffman, S., Gnys, M., Paty, J., \& Zettler-Segal, M. (1994). Psychosocial and personality differences in chippers and regular smokers. Addictive Behaviors, 19, 565-575. doi:10.1016/0306-4603(94)90012-4

Kasvikis, Y., Bradley, B., Powell, J., Marks, I., \& Gray, J. A. (1991). Postwithdrawal exposure treatment to prevent relapse in opiate addicts: A pilot study. International Journal of the Addictions, 26, 1187-1195. doi:10.3109/ 10826089109062154

Kick, S. D., \& Cooley, D. D. (1997). Depressive, not anxiety symptoms are associated with current cigarette smoking among university internal medical patients. Psychosomatics, $38,132-139$.

Killen, J. D., Fortmann, S. P., Kraemer, H. C., Varady, A., \& Newman, B. (1992). Who will relapse? Symptoms of nicotine dependence predict long-term relapse after smoking cessation. Journal of Consulting and Clinical Psychology, 60, 797-801. doi:10.1037//0022-006X.60.5.797
Lee, J. H., Ku, J., Kim, K., Kim, B., Kim, I. Y., Yang, B. H., et al. (2003). Experimental application of virtual reality for nicotine craving through cue exposure. CyberPsychology \& Behavior, 6, 275-280. doi:10.1089/109493103322011560

Lee, J. H., Ku, J. G., Kim, K., Yang, B. H., Kim, S. H., Wiederhold, B. K., et al. (2003). Experimental application of virtual reality for nicotine craving through cue exposure. Paper presented at the 1st Annual Cybertherapy Advanced Technologies in the Behavioral Social and Neurosciences Conference, San Diego, California.

Mantovani, F., \& Castelnuovo, G. (2003). Sense of presence in virtual training: Enhancing skills acquisition and transfer of knowledge through learning experience in virtual environments. In G. Riva, F. Davide, \& W. A. IJsselsteijn (Eds.), Being there: Concepts, effects and measurements of user presence in synthetic environments (pp. 168-181). Amsterdam, The Netherlands: IOS Press.

Marlatt, G. A., \& Gordon, J. R. (1985). Relapse prevention: Maintenance strategies in the treatment of addictive behaviors. New York: Guilford Press.

Mazur, J. E. (1987). An adjusting procedure for studying delayed reinforcement. In M. L. Commons, J. E. Mazur, J. A. Nevin, \& H. Rachlin (Eds.), Quantitative analysis of behavior. Vol. 5: The effects of delay and intervening events on reinforcement value (pp. 55-73). Hillsdale, NJ: Erlbaum.

Mendelson, J. H., Goletiani, N., Sholar, M. B., Siegel, A. J., \& Mello, N. K. (2008). Effects of smoking successive low- and high-nicotine cigarettes on hypothalamic-pituitary-adrenal axis hormones and mood in men. Neuropsychopharmacology, $33,749-760$.

Piasecki, T. M. (2006). Relapse to smoking. Clinical Psychology Review, 26, 196-215. doi:10.1016/j.cpr.2005.11.007

Powell, J., Gray, J., \& Bradley, B. (1993). Subjective craving for opiates: Evaluation of a cue exposure protocol for use with detoxified opiate addicts. British Journal of Clinical Psychology, 32, 39-53. doi:10.1111/j.2044-8260. 1993.tb01026.x

Robillard, G., Bouchard, S., Fournier, T., \& Renaud, P. (2003). Anxiety and presence during VR immersion: A comparative study of the reactions of phobic and non-phobic participants in therapeutic virtual environments derived from computer games. CyberPsychology \& Behavior, 6, 467-476. doi:10.1089/109493103769710497

Rosenberg, H. (2009). Clinical and laboratory assessment of the subjective experience of drug craving. Clinical Psychology Review, 26, 519-534. doi:10.1016/j.cpr. 2009.06.002 
Slater, M., Steed, A., McCarthy, J., \& Maringelli, F. (1998). The influence of body movement on subjective presence in virtual environments. Human Factors, 40, 469-477. doi:10.1518/001872098779591368

Spielberger, C. D., Gorsuch, R. L., \& Lushene, R. E. (1970). Handbook of STAI. Palo Alto, CA: Consulting Psychologists Press.

Tagmat, D., Wolff, J., Ruege, J., John, U., \& Thyrian, J. R. (2010). Predicting the urge to smoke in a population-based sample of adolescent smokers. Substance Use \& Misuse, 45, 1636-1651.

Traylor, A. C., Bordnick, P. S., \& Carter, B. L. (2009). Using virtual reality to assess young adult smokers' attention to cues. CyberPsychology \& Behavior, 12, 373-378. doi:10.3109/ 10826081003754013
Vollstädt-Klein, S., Kobiella, A., Bühler, M., Graf, C., Fehr, C., Mann, K., et al. (2010). Severity of dependence modulates smokers' neuronal cue reactivity and cigarette craving elicited by tobacco advertisement. Addiction Biology, 16, 166175. doi:10.1111/j.1369-1600.2010.00207.x

Watson, N. L., VanderVeen, J. W., Cohen, L. M., DeMarree, K. G., \& Morrell, H. E. R. (2012). Examining the interrelationships between social anxiety, smoking to cope, and cigarette craving. Addictive Behaviors, 37, 986-989. doi:10.1016/j.addbeh.2012.03.025

Yoon, J. H., Higgins, S. T., \& Heil, S. H. (2007). Delay discounting predicts postpartum relapse to cigarette smoking among pregnant women. Experimental and Clinical Psychopharmacology, 15, 176-186. doi:10.1037/1064-1297.

15.2.186 